\title{
AN IMPLICIT 2-D DEPTH-AVERAGED FINITE-VOLUME MODEL OF FLOW AND SEDIMENT TRANSPORT IN COASTAL WATERS
}

\author{
Weiming $\mathrm{Wu}^{1}$, Alejandro Sanchez ${ }^{2}$, and Mingliang Zhang ${ }^{1}$
}

\begin{abstract}
An implicit depth-averaged 2-D finite volume model has been developed to simulate sediment transport and bed morphological changes under actions of currents and waves near coastal inlets. The model computes the depthaveraged 2-D shallow water flow and non-equilibrium transport of total-load sediment, accounting for the effects of wave radiation stresses and turbulent diffusion induced by currents, waves and wave breaking. The model uses a quadtree rectangular mesh to locally refine the mesh around structures of interest or where the topography and/or flow properties change rapidly. The grid nodes are numbered by means of an unstructured index system for more flexibility of mesh generation. The SIMPLEC algorithm is used to handle the coupling of water level and velocity and the Rhie and Chow's (1983) momentum interpolation method is adopted to determine the intercell fluxes on nonstaggered grid. Well-developed longshore current and wave setup determined with the reduced 1-D momentum equations are used as the cross-shore boundary conditions. The model has been tested in several laboratory and field cases, showing good performance. In particular, it can use a long time step and is efficient in computation on a PC platform. It has a potential for simulation of long-term coastal morphodynamic processes.
\end{abstract}

Keywords: Shallow water flow, sediment transport, two-dimensional, finite volume method, quadtree rectangular mesh

\section{INTRODUCTION}

A coastal inlet connects an ocean or sea through a typically narrow landmass to a bay, estuary, lagoon, or river. It is usually a vital navigation link and central for exchange of water, sediments, and nutrients between its two sides. It often experiences multiple-scale interacting forces, such as waves, wind, tide, river flow, and density current, and undergoes very complex morphodynamic processes. Prediction of these processes has been a challenging but crucial task for coastal sediment management and navigation channel maintenance.

Numerous computational models have been developed in recent decades for coastal hydrodynamic and morphodynamic processes (e.g., Chesher et al. 1993, Roelvink and Banning 1994, Ranasinghe et al. 1999, Cayocca 2001, Fortunato and Olveira, 2003, Warner et al. 2008). Most of these models are based on the assumption that bed load or suspended load are instantaneously in equilibrium with the forcing processes on each computational node. However, because of the dynamic nature of currents and waves on the coast, neither bed load nor suspended load is usually in an equilibrium state. The nonequilibrium transport modeling is widely used in river sedimentation (Han 1980, Phillips and Sutherland 1989, and Wu 2008) and has been recently extended to coastal sedimentation (e.g., Sanchez and $\mathrm{Wu} 2010$ ). This approach renounces the assumption of local equilibrium and simulates sediment transport more realistically.

In the past years, the Coastal Modeling System (CMS) for nearshore hydrodynamic and morphodynamic processes has been developed under the Coastal Inlets Research Program (CIRP) of U. S. Army Corps of Engineers (Militello et al. 2004, Buttolph et al. 2006, Sanchez and Wu 2010). The existing CMS hydrodynamic model (called CMS-Flow) solves the 2-D shallow water equations and equilibrium/non-equilibrium total-load sediment transport using an explicit finite volume method (FVM) on structured rectangular mesh. The CMS-Flow is two-way coupled with the spectral wave transformation model called CMS-Wave, which solves the steady-state wave-action balance equation on a Cartesian grid with a finite difference scheme and considers wind wave generation and growth, diffraction, reflection, dissipation due to bottom friction, white capping and breaking, wave-wave and wave-current interactions, wave runup, wave setup, and wave transmission through structures (Lin et al. 2008).

To improve the CMS-Flow model's computational efficiency, an implicit depth-averaged 2-D scheme has been recently implemented in the CMS to solve the shallow water flow and sediment transport equations based on a quadtree rectangular mesh. The flow equations are solved within the FVM with the SIMPLEC algorithm (van Doormaal and Raithby 1984) on non-staggered grid to handle the coupling of water level and velocity, as presented by Wu et al. (2010) in detail. This implicit model

\footnotetext{
${ }^{1}$ National Center for Computational Hydroscience and Engineering, The University of Mississippi, 327 Old Chemistry Building, University, MS 38677, USA

${ }^{2}$ Coastal and Hydraulics Laboratory, U. S. Army Corps of Engineers Research and Development Center, Vicksburg, MS 39180, USA
} 
has been enhanced by implementing several new approaches for model parameters and capabilities, such as wave/current interaction, bottom friction, cross-shore boundary condition, and sediment transport. These enhancements are described in this paper.

\section{FLOW AND SEDIMENT TRANSPORT EQUATIONS}

The depth-averaged shallow water equations in the Cartesian coordinate system are written as:

$$
\begin{gathered}
\frac{\partial h}{\partial t}+\frac{\partial(h u)}{\partial x}+\frac{\partial(h v)}{\partial y}=0 \\
\frac{\partial(h u)}{\partial t}+\frac{\partial(h u u)}{\partial x}+\frac{\partial(h u v)}{\partial y}=-g h \frac{\partial \eta}{\partial x}+\frac{\partial}{\partial x}\left(v_{t} h \frac{\partial u}{\partial x}\right)+\frac{\partial}{\partial y}\left(v_{t} h \frac{\partial u}{\partial y}\right)+\frac{1}{\rho}\left(\tau_{S x}+\tau_{w x}-\tau_{b x}\right)+f_{c} h v \\
\frac{\partial(h v)}{\partial t}+\frac{\partial(h u v)}{\partial x}+\frac{\partial(h v v)}{\partial y}=-g h \frac{\partial \eta}{\partial y}+\frac{\partial}{\partial x}\left(v_{t} h \frac{\partial v}{\partial x}\right)+\frac{\partial}{\partial y}\left(v_{t} h \frac{\partial v}{\partial y}\right)+\frac{1}{\rho}\left(\tau_{S y}+\tau_{w y}-\tau_{b y}\right)-f_{c} h u
\end{gathered}
$$

where $t$ is the time; $x$ and $y$ are the horizontal Cartesian coordinates; $h$ is the total flow depth; $u$ and $v$ are the depth-averaged flow velocities in $x$ - and $y$-directions, respectively; $\eta$ is the water surface elevation above the reference sea level; $g$ is the gravitational acceleration; $\rho$ is the density of flow; $v_{t}$ is the eddy viscosity due to turbulence; $\tau_{S x}$ and $\tau_{S y}$ are the wave radiation stresses, $\tau_{b x}$ and $\tau_{b y}$ are the bed shear stresses, $\tau_{w x}$ and $\tau_{w y}$ are the wind driving forces, all in the $x$ - and $y$-directions, respectively; and $f_{c}$ is the Coriolis force coefficient. Determination of the wind driving force and the wave radiation stresses refers to Buttolph et al. (2006) and Lin et al. (2008).

The moving sediment (total load) in the water column is traditionally divided into suspended load and bed load. The bed load moves by rolling, sliding and saltating in a thin layer of a few particle sizes above the bed, whereas the suspended load is transported by the turbulent flow in the water column above the bed-load layer. To reduce the number of differential equations to be solved, the established model combines the bed-load and suspended load as total load (bed-material load) and uses the following equation to compute the transport of the total load and the resulting bed changes:

$$
\begin{aligned}
& \frac{\partial}{\partial t}\left(\frac{h C_{t}}{\beta_{t}}\right)+\frac{\partial\left(u_{i} h C_{t}\right)}{\partial x_{i}}=\frac{\partial}{\partial x_{i}}\left[v_{s} h \frac{\partial\left(r_{s} C_{t}\right)}{\partial x_{i}}\right]+\alpha_{t} \omega_{f}\left(C_{t^{*}}-C_{t}\right) \\
& \left(1-p_{m}^{\prime}\right) \frac{\partial \zeta}{\partial t}=\alpha_{t} \omega_{f}\left(C_{t}-C_{t^{*}}\right)+\frac{\partial}{\partial x_{i}}\left[D_{s} U_{c} h\left(1-r_{s}\right) C_{t} \frac{\partial \zeta}{\partial x_{i}}\right]
\end{aligned}
$$

where $x_{i}$ is the horizontal coordinate with subscript $i=1$ and 2 representing the $x$-and $y$-directions, respectively; $u_{i}$ is the depth-averaged current velocity in the $i$-th direction; $C_{t}$ is the depth-averaged total-load concentration; $\beta_{t}$ is a correction factor as the ratio of depth-averaged sediment and flow velocities; $v_{s}$ is the sediment diffusion coefficient, assumed to be proportional to the turbulent eddy viscosity as $v_{s}=v_{t} / \sigma_{s}$ with $\sigma_{s}$ being the Schmidt number; $r_{s}$ is the ratio of suspended load to total load, which appears in the diffusion term to account for only the diffusion of suspended load and is determined with the van Rijn sediment transport equations; $\omega_{f}$ is the sediment fall velocity; $C_{t^{*}}$ is the depth-averaged total-load concentration at the equilibrium state, determined with one of the sediment transport formulae available in the model, developed by Watanabe (1987), Soulsby (1997), Lund-CIRP (Camenen and Larson 2007), or van Rijn (2007a, b); $U_{c}$ is the depth-averaged resultant current velocity $U_{c}=\sqrt{u^{2}+v^{2}} ; \alpha_{t}$ is the total-load adaptation coefficient, determined by $\alpha_{t}=U_{c} h /\left(L_{t} \omega_{f}\right)$, with $L_{t}$ being the total-load adaptation length; $\zeta$ is the bed surface elevation; and $D_{s}$ is a function of the flow and sediment characteristics.

The depth-averaged total-load concentration in Eq. (4) is defined as $C_{t}=\int_{0}^{h} u_{c} c d z / U_{c} h$, where $c$ is the local sediment concentration and $u_{c}$ is the stream-wise local current speed. With this definition, the sediment transport is simply $q_{t}=U_{c} h C_{t}$. 
The correction factor is defined as $\beta_{t}=\int_{0}^{h} u_{c} c d z /\left(U_{c} \int_{0}^{h} c d z\right)$, which accounts for the time lag (hysteresis) between flow and sediment transport. It has a value close to unity for fine sediments, but decreases with increasing grain size. Its evaluation can be found in $\mathrm{Wu}$ (2008).

In addition, the model can handle hard bottom and bottom avalanching.

\section{BOTTOM FRICTION}

Bed shear stress experienced by the current in the case where both waves and current coexist is determined by

$$
\begin{aligned}
& \tau_{b x}=c_{f} \rho\left(u^{2}+v^{2}+0.5 U_{w m}^{2}\right)^{1 / 2} u \\
& \tau_{b y}=c_{f} \rho\left(u^{2}+v^{2}+0.5 U_{w m}^{2}\right)^{1 / 2} v
\end{aligned}
$$

where $U_{w m}$ is the maximum orbital bottom velocity of wave; and $c_{f}=g n^{2} / h^{1 / 3}$, in which $n$ is Manning's roughness coefficient.

\section{TURBULENCE CLOSURE}

The eddy viscosity may be affected by current, waves, and wave breaking in coastal waters. A simple linear combination of these three components of eddy viscosity is used in this study, as described below:

$$
v_{t}=v_{t, c}+v_{t, w}+v_{t, b}
$$

where the subscripts $c, w$, and $b$ indicate current, waves, and wave breaking, respectively. The current eddy viscosity $v_{t, c}$ can be determined using several turbulence models, including the depth-averaged parabolic eddy viscosity model and the modified mixing length model. The modified mixing length model is the combination of the depth-averaged parabolic eddy viscosity model and the mixing length model (Wu, 2008):

$$
v_{t, c}=\sqrt{\left(\alpha_{0} u_{*} h\right)^{2}+\left(l_{h}^{2}|\bar{S}|\right)^{2}}
$$

where $|\bar{S}|=\left[2(\partial u / \partial x)^{2}+2(\partial v / \partial y)^{2}+(\partial u / \partial y+\partial v / \partial x)^{2}\right]^{1 / 2} ; \alpha_{0}$ is an empirical coefficient, set as $\kappa / 6$, with $\kappa$ being the von Karman constant; $l_{h}$ is the horizontal mixing length, determined by $l_{h}=\kappa \min \left(c_{m} h, y\right)$, with $y$ being the distance to the nearest wall and $c_{m}$ an empirical coefficient between 0.3-1.2. Eq. (9) takes into account the effects of bed shear and horizontal velocity gradients respectively through the first and second terms on its right-hand side. It has been found that the modified mixing length model is better than the depth-averaged parabolic eddy viscosity model that accounts for only the bed shear effect.

Waves contribute significantly to lateral mixing, particularly in the surf zone. The eddy viscosity due to waves is determined using the Kraus and Larson (1991) formula:

$$
v_{t, w}=\Lambda u_{m} H
$$

where $\Lambda$ is an empirical coefficient representing the lateral mixing strength, $H$ is the wave height, and $u_{m}$ is the amplitude of the horizontal component of the wave orbital velocity at the bottom.

Wave breaking also generates a significant amount of turbulent eddies in the surf zone. Its contribution to eddy viscosity is determined with

$$
v_{t, b}=k_{b}\left(\frac{D_{b}}{\rho}\right)^{1 / 3} h, \text { or } v_{t, b}=\alpha_{b}\left(\frac{\tau_{S}}{\rho}\right)^{1 / 2} h
$$

where $D_{b}$ is the energy dissipation rate due to wave breaking, $\tau_{S}$ is the wave radiation stress, and $k_{b}$, $\alpha_{b}$ are two empirical coefficients. The CMS allows application of both formulae; the first formula is 
used by several researchers (e.g., Camenen and Larson 2007), whereas the second formula considers the similarity between the effects of bed shear stress and wave radiation stress on turbulence. The second formula is used in the test cases presented in this paper.

\section{BOUNDARY CONDITIONS}

For a well-defined problem governed by Eqs. (1)-(3), the flow discharge or velocity is needed at inflow boundaries, while the water level is usually given at outflow boundaries for a subcritical flow or at inflow boundaries for a supercritical flow. In the context of coastal waters, the water surface elevation is usually specified at seaward boundary, which can be the time series of tide levels recorded at the boundary, generated using the harmonic analysis of tidal constituents, or predicted using a largerscale regional model. Flow discharge is usually given at a river inflow boundary, if there is one such boundary.

Along a cross-shore boundary, it is assumed that a well-developed longshore current exists. Thus, the $y$ (alongshore) momentum equation can be reduced from Eq. (3) as follows:

$$
0=\frac{\partial}{\partial x}\left(v_{t} h \frac{\partial v}{\partial x}\right)+\frac{1}{\rho}\left(\tau_{S y}+\tau_{w y}\right)-c_{f} U_{c w} v
$$

where $U_{c w}=\left(u^{2}+v^{2}+0.5 U_{w m}^{2}\right)^{1 / 2}$. Eq. (12) prescribes $v$, the alongshore component of current velocity, which is used as the boundary condition at the cross-shore boundary. The cross-shore $(x)$ component of the velocity may be copied from internal nodes.

The water level setup due to waves and winds at the cross-shore boundary can be determined by assuming a zero alongshore gradient of water level, or using the following equation reduced from the $x$ (cross-shore) momentum equation (2):

$$
0=-\rho g h \frac{\partial \eta}{\partial x}+\tau_{S x}+\tau_{w x}
$$

Near rigid wall boundaries, such as beaches and islands, the wall-function approach is employed (Wu, 2008). A threshold flow depth (a small value such as $0.02 \mathrm{~m}$ in field cases) is used to judge drying and wetting. If the flow depth on a node is larger than the threshold value, this node is considered to be wet; otherwise, this node is dry. Because a fully implicit solver is used in the present model, all the wet and dry nodes participate in the solution. Dry nodes are assigned a zero velocity. The wall-function approach is applied on the water edges between the dry and wet nodes.

\section{NUMERICAL SOLUTION ALGORITHMS}

The present model uses a multiple-level quadtree rectangular mesh, which can locally refine the mesh around structures or in high-gradient regions by splitting a coarse cell into four child cells and using as many levels of refinement as necessary, as shown in Figure 1. This quadtree mesh can improve the accuracy of the model with a relatively small increase in number of cells. The grid points are numbered by means of an unstructured index system, so that the mesh can be flexibly generated while it has the merits of the traditional rectangular mesh.

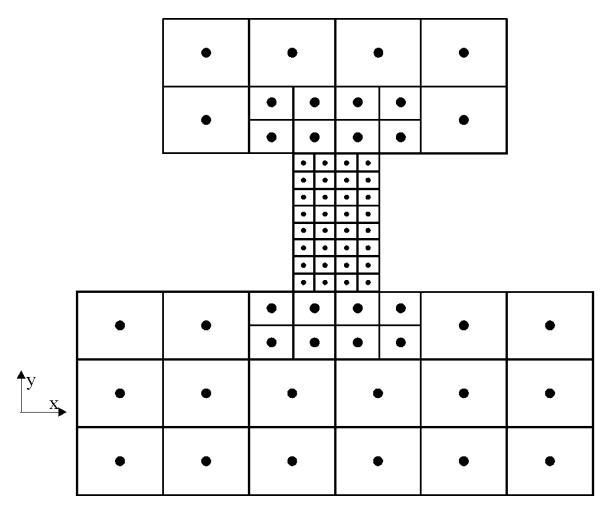

Figure 1. Example of quadtree mesh system 
The model uses the non-staggered grid system and stores primary variables $u$-, $v$-velocity, and water level on the same set of grid points. The convective terms in the momentum equations are discretized using one of the hybrid upwind/central difference, exponential difference, and HLPA schemes. The HLPA scheme has second order accuracy in space, while the other two have the accuracy between first and second orders. The SIMPLEC algorithm with under-relaxation is used to handle the coupling of water level and velocity and achieve high numerical stability and efficiency. Fluxes at cell faces are determined using Rhie and Chow's (1983) momentum interpolation method, to avoid spurious checkerboard oscillations. The discretized algebraic equations with sparse, asymmetric matrices of coefficients are solved iteratively using the flexible GMRES method with ILUT preconditioning. Details of the numerical methods can be found in Wu et al. (2010).

The sediment transport model solves the convection-diffusion equation with the same finite volume method on the quadtree rectangular mesh as that used by the flow model.

\section{MODEL TESTING}

Four cases were used in this study to demonstrate the performance of the developed model. They concern the longshore current generated by waves on a sloped beach, tidal flow in an estuary, erosion due to clear water inflow in a wide basin, and flow and sediment transport near a coastal inlet. The simulation results in these test cases are described below.

\section{Case 1: Alongshore Current Generated by Waves on a Beach}

Visser (1982) conducted laboratory experiments of monochromatic waves on a planar beach and collected measurements on waves, currents and water levels. Visser's Case 4 was used to validate the developed model. The bathymetry consisted of a 1:10 slope for the first $1-\mathrm{m}$ seaward distance, a 1:20 slope for the next 5-m distance, followed by a $5.9 \mathrm{~m}$ distance of flat bottom to the wave generator. The incident wave had a height of $0.078 \mathrm{~m}$, peak period of $1.02 \mathrm{sec}$ and a wave angle of $15.4^{\circ}$. Case 4 was run over a concrete bed. A mesh consisting of 84 rows and 147 columns was used with a constant grid resolution of $0.15 \mathrm{~m}$ in the longshore direction and a variable grid resolution between 0.04 and $0.15 \mathrm{~m}$ in the cross-shore direction. A zero water level was forced at the offshore boundary. Figures 2-4 compare the calculated and measured longshore currents, water levels and wave heights, respectively. The calculated water level and wave height agree well with measured data, with root mean squared errors (RMSE) of 0.001 and $0.009 \mathrm{~m}$, respectively. The magnitude of the longshore current is accurately predicted, but the location of the maximum longshore current is not. The reason is that the model used in this study does not consider the effect of roller.

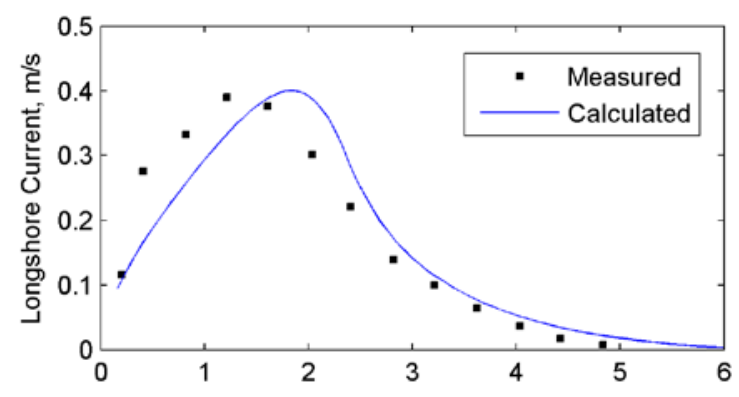

Figure 2. Comparison of measured and computed longshore currents for Visser Case 4 (RMSE $=0.051 \mathrm{~m} / \mathrm{s}$ ).

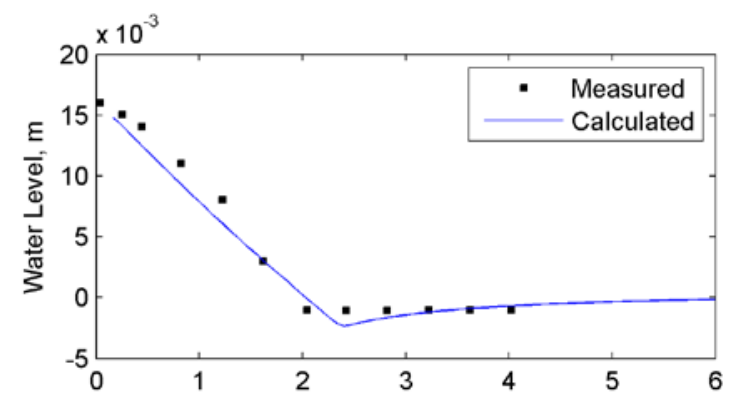

Figure 3. Comparison of measured and computed water levels for Visser Case 4 (RMSE $=0.001 \mathrm{~m}$ ). 


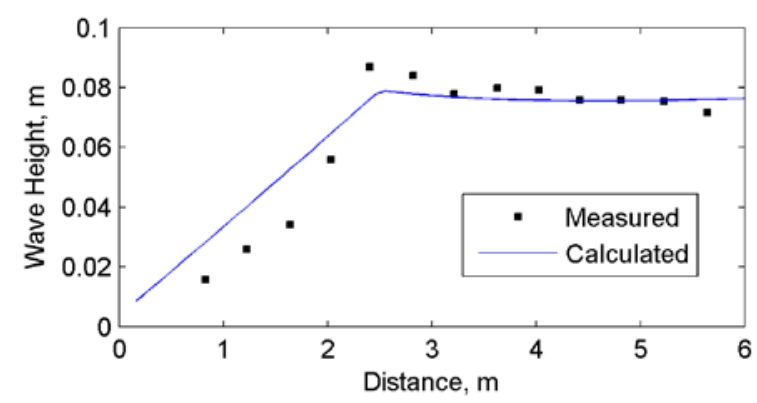

Figure 4. Comparison of measured and computed wave heights for Visser Case 4 (RMSE $=0.009 \mathrm{~m}$ ).

\section{Case 2: Tidal Flow in Gironde Estuary}

The Gironde Estuary is located in southwestern France. It receives runoff from the Garonne River and the Dordogne River and empties into the Atlantic Ocean, as shown in Figure 5. The water-surface width varies from 2 to $14 \mathrm{~km}$, and the flow depth in the navigation channel is about 6-30 m. The estuary is partially mixed and macrotidal, with a 12 hour and 25 minutes tidal lunar period and a tidal amplitude of $1.5-5 \mathrm{~m}$ at the mouth ( $\mathrm{Li}$ et al. 1994). The simulation domain is about $80 \mathrm{~km}$ long, from the mouth to the Garonne River and the Dordogne River. Because the domain is relatively simple, a uniform mesh with a grid spacing of $250 \times 125 \mathrm{~m}$ is used. The data measured from May 19 to 25, 1975 are used to validate the model. The computational time step is 30 minutes. The Manning's $n$ is set as 0.015 .

Figure 6 shows the calculated flow fields in flood and ebb tides. Figure 7 compares the measured and calculated water levels at stations Ile Verte and Richard, and Figure 8 compares the measured and calculated flow velocities at stations Pauillac and Richard. The measured flow velocities are $1 \mathrm{~m}$ under the water surface and $1 \mathrm{~m}$ above the river bed. The amplitude and phase of both water level and flow velocity are well predicted by the numerical model. No obvious phase difference exists between the measured data and simulated results.

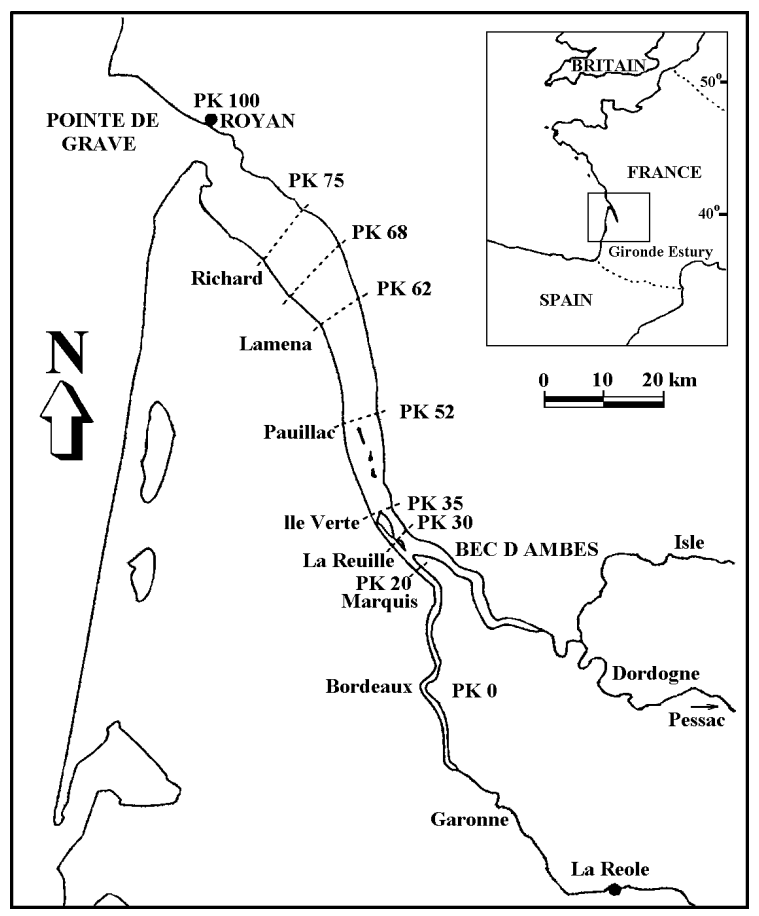

Figure 5. Sketch of Gironde Estuary, France 


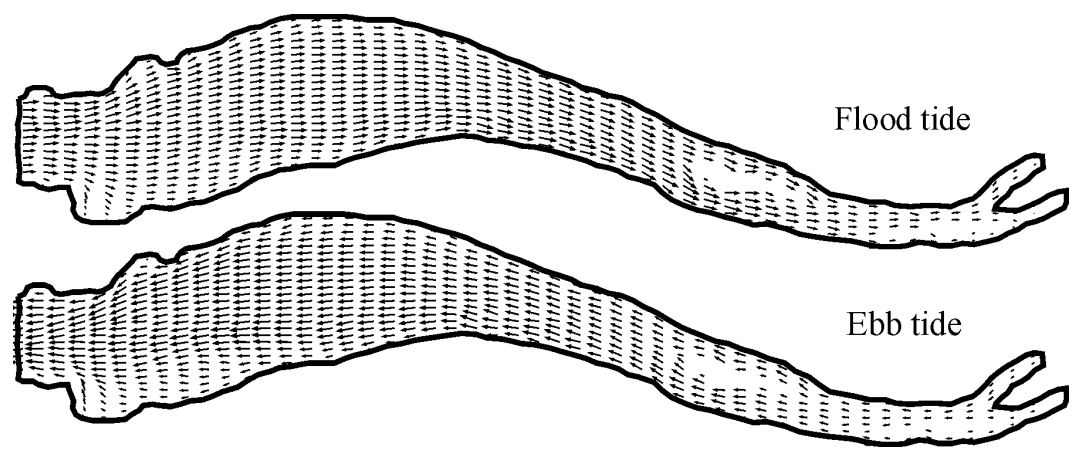

Figure 6. Calculated flow patterns in flood and ebb tides at Gironde Estuary
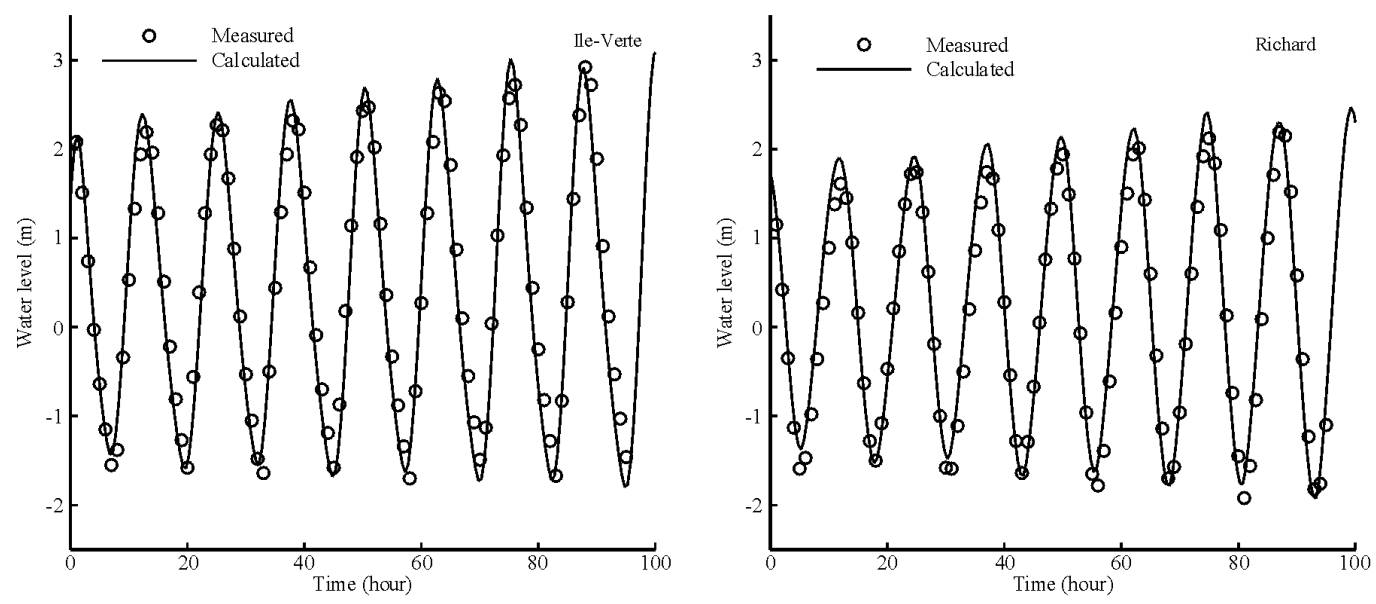

Figure 7. Measured and calculated water levels at selected stations in Gironde Estuary
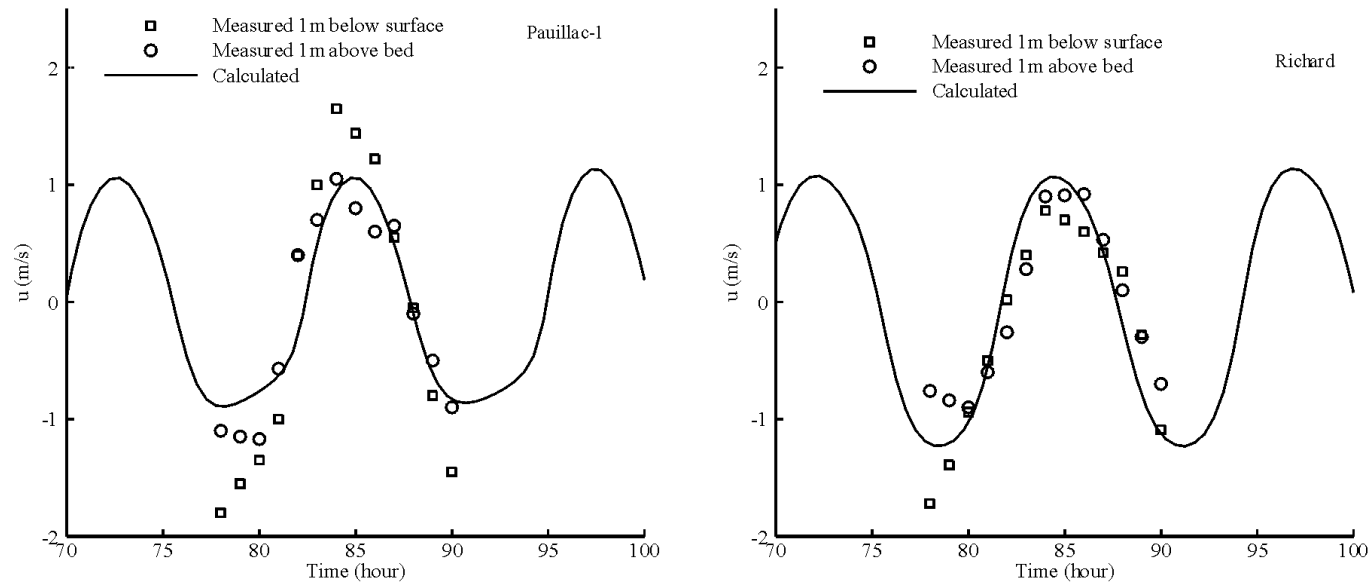

Figure 8. Measured and calculated velocities at selected stations in Gironde Estuary

\section{Case 3: Erosion due to Clear Water Inflow in a Basin}

Thuc (1991) carried out an experimental study on the erosion process in a rectangular basin with a loose bed due to clear water inflow from a narrow channel. The rectangular basin was $5 \mathrm{~m}$ long and $4 \mathrm{~m}$ wide. It was connected with a $0.2 \mathrm{~m}$ wide and $2 \mathrm{~m}$ long channel in the upstream and a $1.2 \mathrm{~m}$ wide and $1.0 \mathrm{~m}$ long channel in the downstream. It had a concrete bed covered with a $0.16 \mathrm{~m}$-thick layer of fine sand, which had a settling velocity of $0.013 \mathrm{~m} / \mathrm{s}$. The inflow velocity in the upstream channel was 0.6 
$\mathrm{m} / \mathrm{s}$, and the water depth at the outlet was $0.15 \mathrm{~m}$. The Manning roughness coefficient in the basin was estimated as 0.03 .

The computational domain is shown in Figure 9. The mesh consisted of 62 rows and 69 columns, with finer grid spacing around the centerline. The time step for sediment calculation was 30 seconds. The transport equation which best fit the measurements was the Soulsby-van Rijn formula (Soulsby 1997). Figure 10 shows the calculated flow pattern in the domain and bed change contours around the inflow region at the center part of the basin after the elapsed time of $4 \mathrm{hr}$. Erosion happens due to the inflow of clear water, and the eroded sediment moves downstream and deposits forming a dune feature. Figure 11 compares the measured and calculated bed changes along the longitudinal centerline at 1 and $4 \mathrm{hr}$. The calculated erosion and deposition depths are in good agreement with the measured data, in particular at time $4 \mathrm{hr}$. The RMS error is 0.014 and $0.012 \mathrm{~m}$ for times 1 and $4 \mathrm{hr}$, respectively.

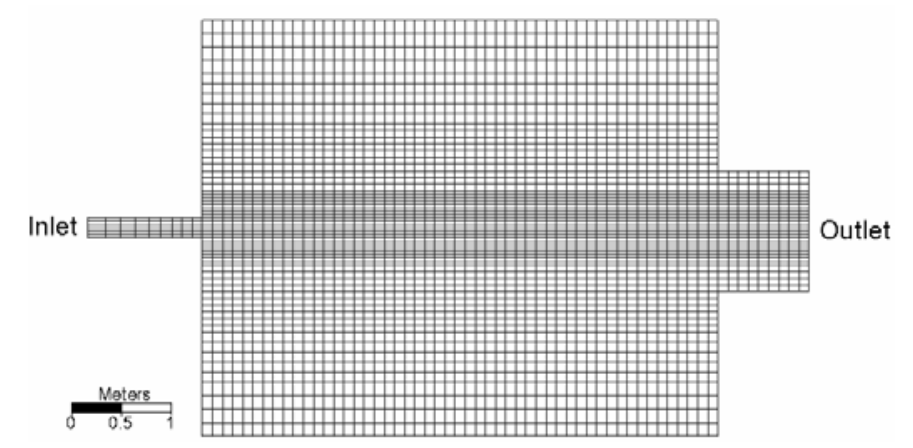

Figure 9. Computational domain and mesh for Thuc (1991) erosion case

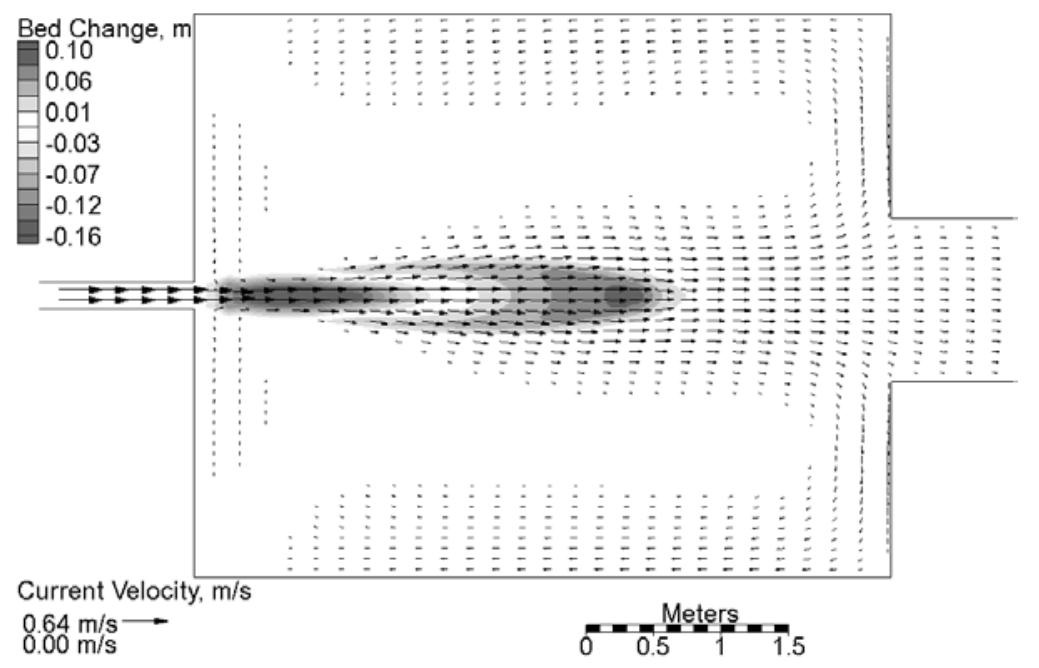

Figure 10. Calculated flow field and bed change at the elapsed time of $4 \mathrm{hr}$ in Thuc (1991) case

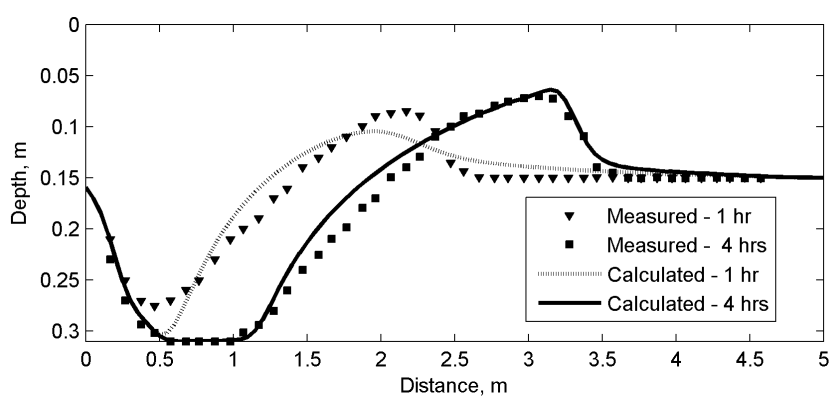

Figure 11. Calculated and measured bed changes along the centerline of the basin in Thuc (1991) case at 1 $($ RMSE $=0.014 \mathrm{~m})$ and $4 \mathrm{hrs}(\mathrm{RMSE}=0.012 \mathrm{~m})$. 


\section{Case 4: Flow and Sediment Transport in Grays Harbor}

Grays Harbor is located on the southwest Washington coast about 45 miles north of the Columbia River. The estuary has a wetted surface area of approximately 91 square miles at mean higher high water and 28 squares miles at mean lower low water. The main input of fresh water is from the Chehalis River. The 3 mile wide entrance has two convergent rock jetties which extend from spit points, as shown in Figure 12.

The computational grid consisted of 67,000 cells and had a non-uniform spacing from 28 to $200 \mathrm{~m}$. Both the wave and flow models used the same grid. The spectral waves from the NOAA buoy 46029 were input at the model boundaries every 3 hours. Wind from the same buoy was included in the wave model. The hydrodynamic, sediment transport and morphologic time steps were set to 15 minutes. Different time steps between 5-30 minutes were tested and the differences were negligible. The Manning's n coefficient was calibrated as 0.018 using field measurements. The hydrodynamic model was forced with water level measurements taken at Station 0 . The bed was modeled with a constant grain size of $0.3 \mathrm{~mm}$. The Lund-CIRP formula was used to calculate the sediment transport capacity. Finally the total load adaptation length was set to a constant value of $10 \mathrm{~m}$. The 27-day period from September 14 to October 15 of 1999 was calculated with CMS.

Figures 13-15 compare the computed and measured water levels, current velocities and wave heights at selected stations. The measured data were obtained from Osborne et al. (2002). The agreement between those calculated results and measured data is generally good. Figure 16(a) shows the computed 27-day morphology change from September to October of 1999. The regions of erosional and depositional trends are approximately indicated by polygons and ellipses. Although direct measurements of the morphology change during the same period are not available, the morphology change from 1993 to 2005 is shown in Figure 16(b) as a reference of the morphological trends. One can see the locations of erosion and deposition in the estuary are generally well predicted. Considering the long-term bed changes measured had been affected by many complicated factors, such as dredging and jetty breach, it is difficult to compute the morphological changes in this long-term period. This case study application of the CMS model will be further discussion in a subsequent publication.

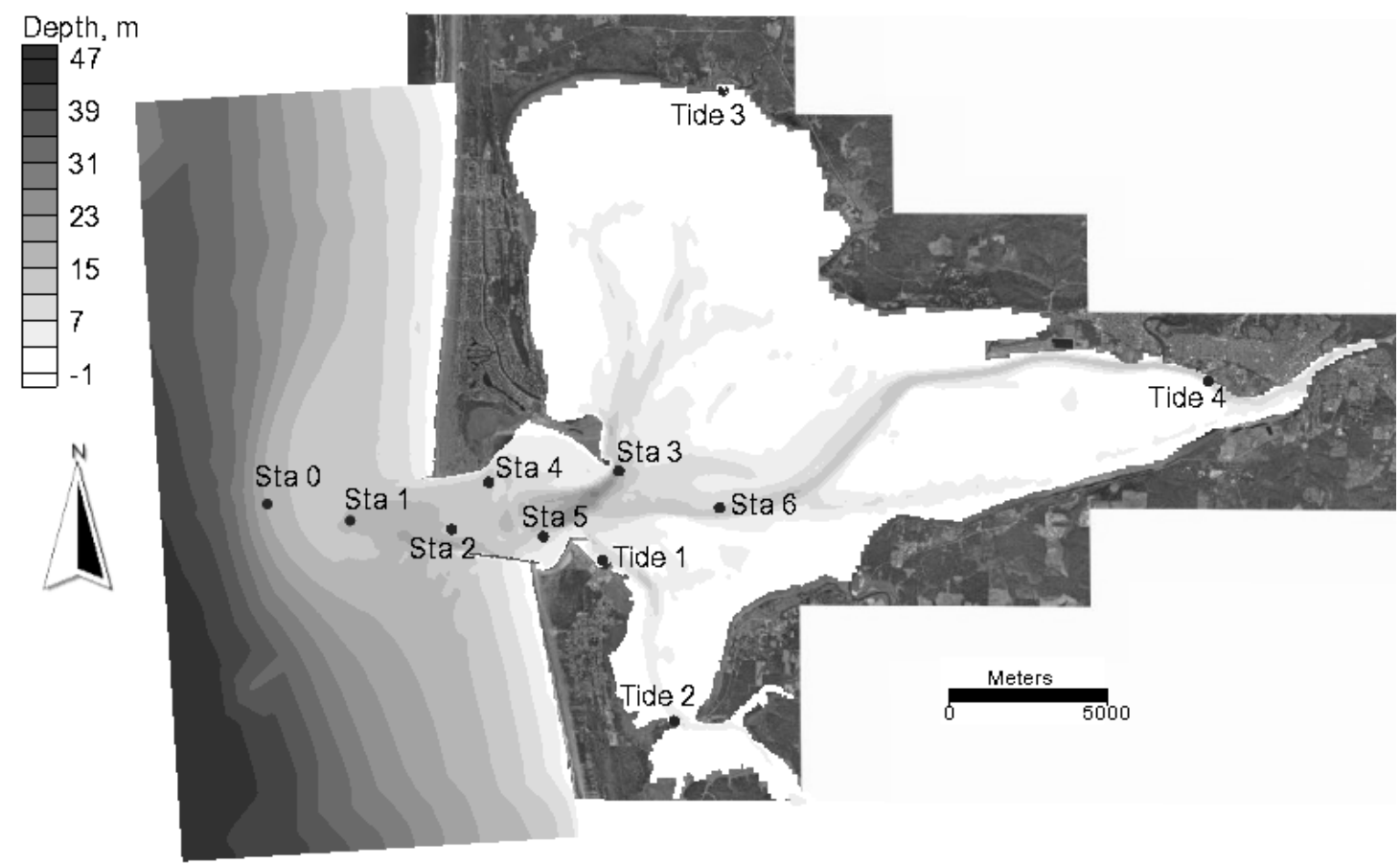

Figure 12. Topography and measurement stations at Grays Harbor. 


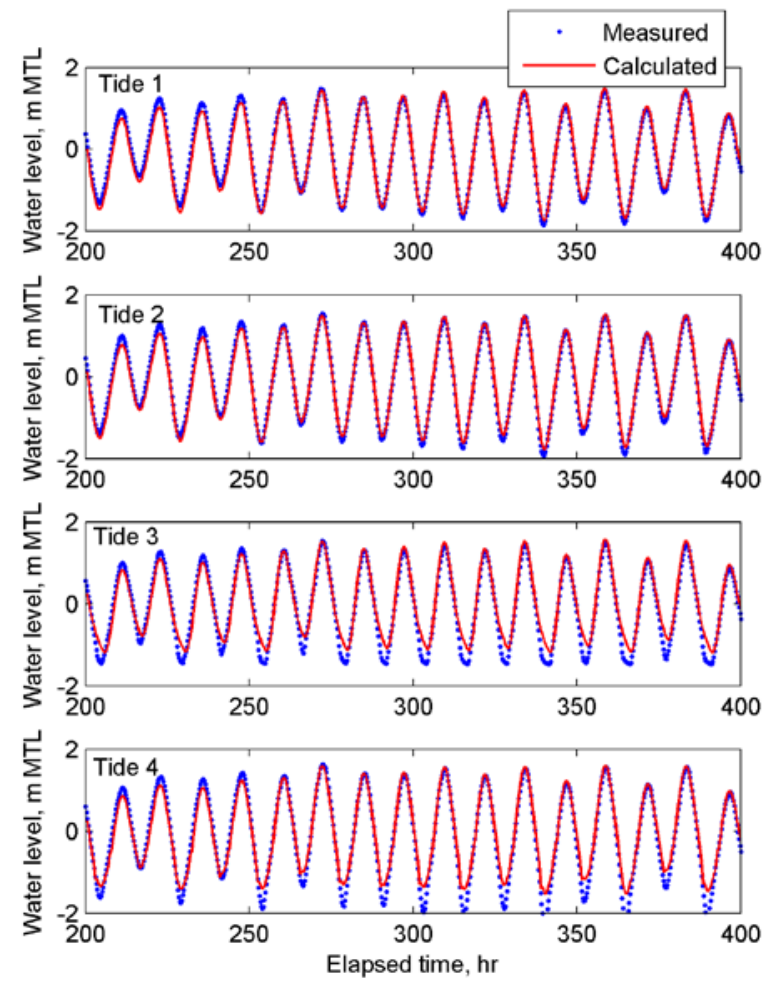

Figure 13. Measured and calculated tide levels at Grays Harbor, where MTL = Mean Tide Level (from top to bottom RMSE $=0.087,0.099,0.219,0.198 \mathrm{~m}$ ).

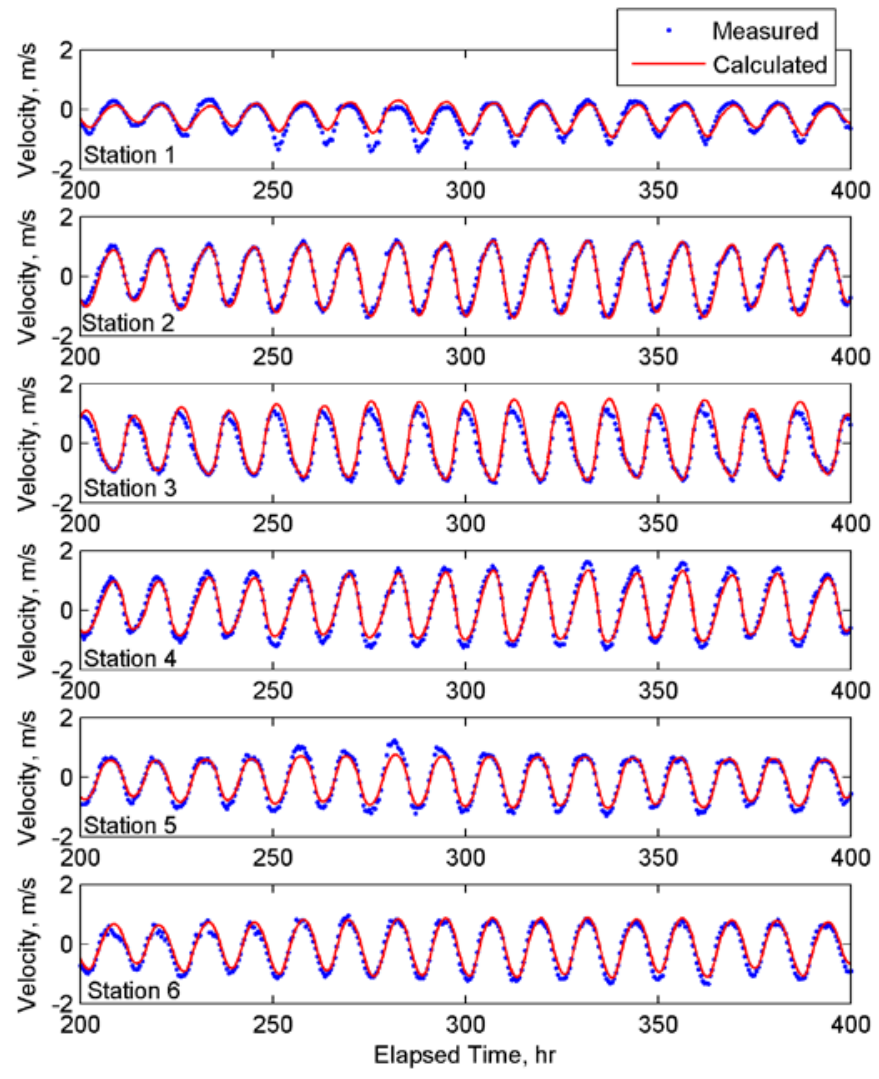

Figure 14. Measured and calculated current velocities at Grays Harbor (from top to bottom RMSE $=0.181$, $0.176,0.207,0.1840 .153,0.165 \mathrm{~m} / \mathrm{s}$ ). 

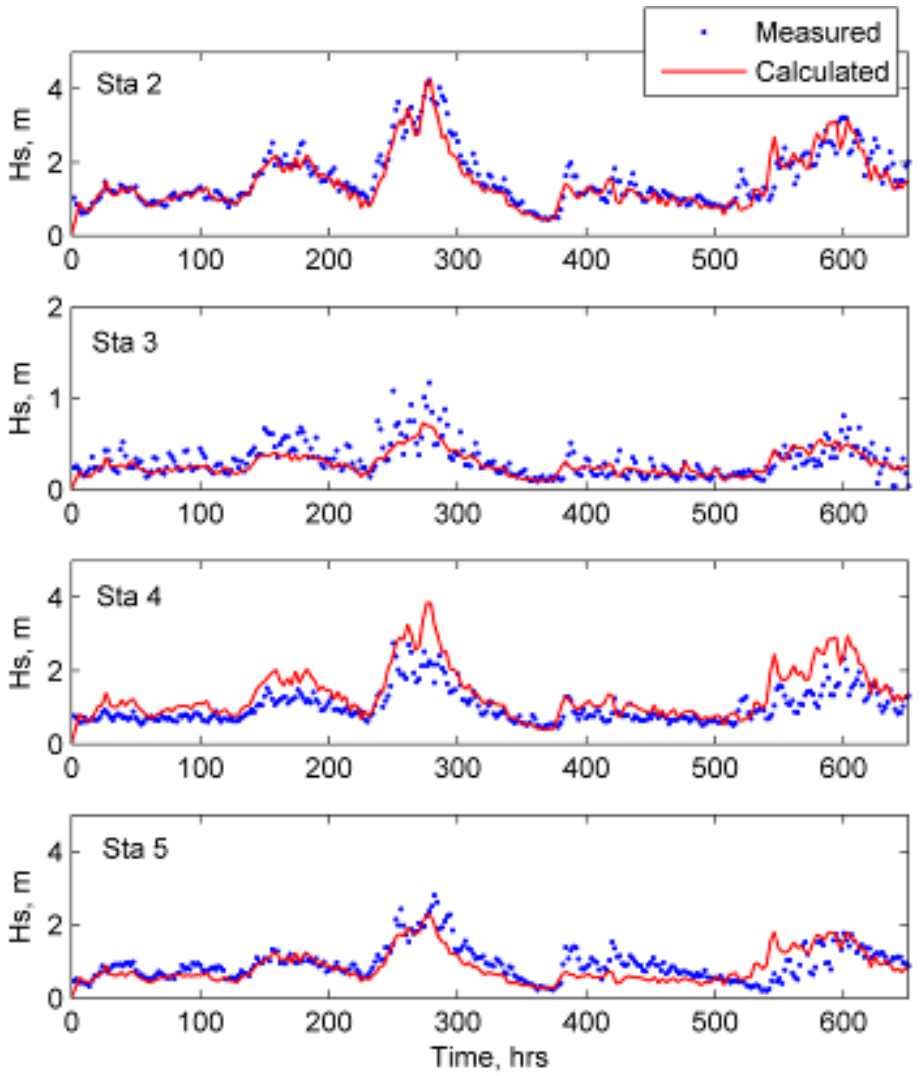

Figure 15. Measured and calculated wave heights at Grays Harbor (from top to bottom RMSE $=0.325,0.121$, $0.501,0.339 \mathrm{~m})$.
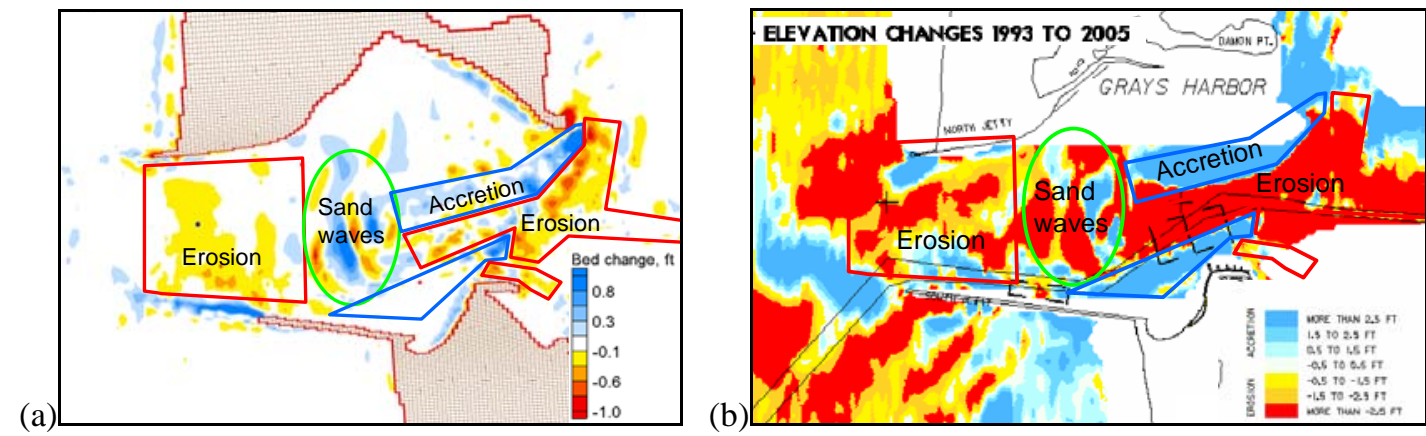

Figure 16. (a) Calculated bed change from September to October of 1999; and (b) Measured bed change in 1993-2005 at Grays Harbor. General trends in calculated morphologic change are represented.

\section{CONCLUSIONS}

This paper presents a depth-averaged 2-D model of flow, sediment transport and bed morphological changes under actions of currents and waves. The model solves the depth-averaged shallow water equations using an implicit finite volume method based on quadtree rectangular mesh. It considers the effects of wave radiation stresses and turbulent diffusion induced by current, waves and wave breaking. The quadtree technology locally refines the mesh around structures of interest or where the topography and/or flow properties change rapidly, and adopts an unstructured index system to number the grid nodes for more flexibility of mesh generation. The model uses the SIMPLEC algorithm with the Rhie and Chow's (1983) momentum interpolation to handle the coupling of water level and velocity on non-staggered grid. It specifies the cross-shore boundary conditions by assuming well- 
developed longshore current and wave setup which are determined with the reduced 1-D momentum equations.

The model computes the non-equilibrium transport of total-load sediment, accounting for sediment entrainment induced by waves and current, the effect of bed slope on bed-load transport, etc. The sediment transport equation is solved using the same finite volume method as that used in the flow model.

The model has been tested extensively in many laboratory and field cases. Presented in this paper are four cases, showing good performance of the model in predicting longshore current generated by waves, clear water erosion in a wide basin, and unsteady tidal flow and sediment transport in estuaries. Because of the unique advanced numerical methods used, the model can use a long time step and is efficient in computation on a PC platform.

The CMS is still under development and will be improved further in the future. For example, the location of the maximum longshore current generated by waves is not well predicted by the present version. A roller model is being implemented to improve this. The transport of multiple-sized sediment mixtures is also considered in the next version of the CMS2D model. Upgrades to the model are planned to incorporate dredging and placement of dredged sediment during the simulation period.

\section{ACKNOWLEDGEMENTS}

This study is supported by the Coastal Inlets Research Program, ERDC, US Army Corps of Engineers, Vicksburg, MS. Drs. Nicholas C. Kraus, Julie D. Rosati, Lihwa Lin, Chris Reed, Alan K. Zundel, Mr. Mitchell Brown, Miss Qianru Lin and other colleagues in the CIRP group are acknowledged for their valuable comments and suggestions.

\section{REFERENCES}

Buttolph, A.M., C.W. Reed, N.C. Kraus, N. Ono, M. Larson, B. Camenen, H. Hanson, T. Wamsley, and A.K. Zundel. 2006. Two-dimensional depth-averaged circulation model CMS-M2D: Version 3.0, Report 2: Sediment transport and morphology change, Technical Report ERDC/CHL TR-06-9, Coastal and Hydraulics Laboratory, ERDC, US Army Corps of Engineers, Vicksburg, MS, USA.

Camenen, B., and M. Larson. 2007. A unified sediment transport formulation for coastal inlet application, Technical Report ERDC-CHL CR-07-01, Coastal and Hydraulics Laboratory, ERDC, US Army Corps of Engineers, Vicksburg, MS, USA.

Cayocca, F. 2001. Long-term morphological modeling of a tidal inlet: the Arcachon Basin, France. Coastal Engineering, 42, 115-142.

Chesher, T.J., H.M. Wallace, I.C. Meadowcroft, and H.N. Southgate. 1993. PISCES, A Morphodynamic Coastal Area Model, First Annual Report, Report SR 337, HR Wallingford, UK.

Forunato, A.B., and A. Olveira. 2003. A modeling system for tidally driven long-term morphodynamics, Journal of Hydraulic Research, 42(4), 626-634.

Han, Q. 1980. A study on the non-equilibrium transportation of suspended load, Proc. First International Symposium on River Sedimentation, Beijing, China.

Li, Z.H., K.D. Nguyen, J.C. Brun-Cottan, and J.M. Martin. 1994. Numerical simulation of the turbidity maximum transport in the Gironde Estuary (France), Oceanologica Acta, 17(5), 479-500.

Lin, L., Z. Demirbilek, H. Mase, J. Zheng, and F. Yamada. 2008. CMS-Wave: A nearshore spectral wave processes model for coastal inlets and navigation projects, Technical Report ERDC/CHL TR08-13, Coastal and Hydraulics Laboratory, ERDC, US Army Corps of Engineers, Vicksburg, MS, USA.

Militello, A., C.W. Reed, A.K. Zundel, and N.C. Kraus. 2004. Two-dimensional depth-averaged circulation model M2D: Version 2.0, Report 1, Technical documentation and user's guide. ERDC/CHL TR-04-2, Coastal and Hydraulics Laboratory, ERDC, US Army Corps of Engineers, Vicksburg, MS, USA.

Kraus, N.C., and M. Larson. 1991. NMLONG - Numerical model for simulating the longshore current. Report 1: Model development and tests, Technical Report DRP-91-1, U.S. Army Engineer Waterways Experiment Station, Vicksburg, MS, USA.

Osborne, P.D., D.B. Hericks, N.C. Kraus, and R.M. Parry. 2002. Wide-area measurements of sediment transport at a large inlet, Grays Harbor, Washington, Proc. 28th Int. Conf. on Coastal Engineering, World Scientific, Cardiff, UK, 1-13.

Phillips, B.C., and A.J. Sutherland. 1989. Spatial lag effects in bed load sediment transport, J. Hydr. Res., IAHR, 27(1), 115-133. 
Ranasinghe, R., C. Pattiaratchi, and G. Masselink. 1999. A morphodynamic model to simulate the seasonal closure of tidal inlets, Coastal Engineering, 37, 1-36.

Rhie, T.M. and Chow, A. 1983. Numerical study of the turbulent flow past an isolated airfoil with trailing-edge separation. AIAA J., 21, 1525-1532.

Roelvink, J.A., and G.K.F.M. van Banning. 1994. Design and development of Delft3D and application to coastal morpholdynamics. Hydrodynamics '94, Verwey, Minns, Babovic \& Maksimovic (eds), Balkema, Rotterdam, 451-455.

Sanchez, A., and W. Wu. 2010. A non-equilibrium sediment transport model for coastal inlets and navigation channels, $J$. Coastal Research, in press.

Soulsby, R. 1997. Dynamics of Marine Sands, Thomas Telford Publications, London.

Thuc, T. 1991. Two-dimensional morphological computations near hydraulic structures, Doctoral Dissertation, Asian Institute of Technology, Bangkok, Thailand.

Van Doormal, J.P., and G.D. Raithby. 1984. Enhancements of the SIMPLE method for predicting incompressible fluid flows, Num. Heat Transfer, 7, 147-163.

Van Rijn, L.C. 2007a. Unified view of sediment transport by currents and waves, I: Initiation of bed motion, bed roughness, and bed-load transport, J. Hydraulic Eng., 133(6), 649-667.

Van Rijn, L.C. 2007b. Unified view of sediment transport by currents and waves, II: Suspended transport, J. Hydraulic Eng., 133(6), 668-689.

Visser, P.J. 1982. Uniform longshore current measurements and calculations, Proc. 19th Coastal Engineering Conference, ASCE, 2,192-2,207.

Warner, J.C., C.R. Sherwood, R.P. Signell, K. Harris, and H.G. Arango. 2008. Development of a threedimensional, regional, coupled wave, current, and sediment-transport model, Computers and Geosciences, 34, 1284-1306.

Watanabe, A. 1987. 3-dimensional numerical model of beach evolution, Proc. Coastal Sediments '87, N.C. Kraus (ed.), ASCE, Reston, VA, 802-817.

Wu, W. 2008. Computational River Dynamics, Taylor \& Francis, UK, 494p.

Wu, W., A. Sanchez, and M. Zhang. 2010. An implicit 2-d shallow water flow model on unstructured quadtree rectangular mesh, J. Coastal Research, in press. 